\title{
TRAJETÓRIA E PERCALÇOS DE UMA SOCIEDADE MÉDICA DE ESPECIALIDADE
}

DESCRITORES - Sociedades médicas. Endoscopia do sistema digestório. Endoscópios gastrointestinais. Contaminação de equipamentos. Desinfecção.

A Sociedade Brasileira de Endoscopia Digestiva - SOBED, que em 25 de julho passado completou 35 anos de existência, constitui entidade civil, sem fins lucrativos, de natureza associativa, organizada nacionalmente por entidades estaduais e sub-estaduais, sendo filiada à Associação Médica Brasileira, à Organização Mundial de Endoscopia Digestiva, à Sociedade Interamericana de Endoscopia Digestiva e regida por estatutos em conformidade com a legislação em vigor.

A diretriz principal, comum a todas as gestões, que sempre teve como objetivo o desenvolvimento na área científica promovendo Congressos, Simpósios, Jornadas, cursos, publicações, criação de centros de treinamento e residências médicas em endoscopia digestiva, levou a SOBED à posição relevante que hoje ocupa, abrindo portas para novas perspectivas dentro dessa importante especialidade diagnóstica e terapêutica.

Neste processo evolutivo e dando sequência às conquistas obtidas, a atual Diretoria Executiva da SOBED, que assumiu suas atividades em novembro de 2008 durante a Semana Brasileira do Aparelho Digestivo, tinha traçado seus objetivos e metas, das quais muitas já foram cumpridas.

Ainda em Brasília, horas após nossa posse, fomos "atropelados" pela informação de que o uso do glutaraldeído a $2 \%$ para desinfecção de endoscópios seria suspenso. A suspensão devia-se ao surto de micobacteriose que atingira seu patamar máximo em 2008, e tinha como agentes infectantes principais a $M$. abcessus e a $M$. massiliense que, em ensaios científicos realizados, mostravam-se resistentes à ação do produto, mesmo no tempo de esterilização preconizado pelo fabricante ( 8 a 10 horas).

Ficou claro em toda a investigação realizada pela Agência Nacional de Vigilância Sanitária - ANVISA, publicada em seu sítio, que as principais causas do surto, que se arrastava desde o ano 2000, eram a limpeza insuficiente e o uso indevido e inadequado do glutaraldeído a $2 \%$ nos instrumentais de cirurgia por vídeo. Todo o instrumental é material crítico e precisaria, além da fundamental limpeza adequada, ser submetido ao processo de esterilização e não de desinfecção.

O único ponto em comum, entre os atos cirúrgicos causadores da micobacteriose e os procedimentos endoscópicos realizados por vias naturais que inclui os atos da endoscopia digestiva, otorrinolaringologia, ginecologia, urologia e pneumologia, era o produto químico desinfetante.

Embora não houvesse até aquela data, como não há até hoje, casos notificados de micobacteriose transmitadas por procedimentos endoscópicos realizados por vias naturais, a proibição seria generalizada. Apesar da ANVISA não ter efetivado a proibição em nenhum momento, as Secretarias de Saúde dos Estados de Santa Catarina e a do Rio de Janeiro, a fizeram por períodos variáveis.

Os fatos relatados desencadearam ações da nossa Sociedade especialmente junto a ANVISA, com início durante o próprio Congresso de Brasília e que continuaram pelos meses subsequentes. Uma grande vitória foi dissociar nossos procedimentos dos atos médicos cirúrgicos por vídeo, dando origem ao que hoje designamos de Procedimentos Endoscópicos por Vias Naturais, terminologia adotada pela ANVISA na RDC n ${ }^{\circ} .8$ de fevereiro de 2009, da qual a SOBED foi a maior protagonista, que exclui esses procedimentos do elenco de sanções impostas aos atos cirúrgicos por vídeo.

O caminho percorrido revelou, entre muitos aprendizados, a situação em que se encontram muitos serviços de endoscopia, especialmente os públicos, onde há carências das mais diversas ordens e a fiscalização das vigilâncias municipais ou estaduais fecham os olhos às evidências gritantes, enquanto atitudes inversas são assumidas quando da fiscalização de serviços privados. Nesses, a discriminação, e muitas vezes a falta de conhecimento, leva a exigências descabidas e distantes do que é de fato necessário em prol da segurança do paciente e do exercício da especialidade pelo médico.

Nesta edição dos ARQUIVOS de GASTROENTEROLOGIA há a apresentação de um trabalho ${ }^{(1)}$ que demonstra essa situação.

A fiscalização sobre o funcionamento dos serviços médicos é atribuição do sistema de vigilância sanitária e dos conselhos de medicina. As sociedades de especialidade não têm este poder, ficando limitadas à intermediação de eventuais reclamações de seus associados que, como regra geral, não formalizam as denúncias de irregularidades por receio de retaliações. Embora haja na SOBED assistência individualizada ao médico associado, o nível de atuação mais eficaz e 
abrangente se faz diretamente nas instituições governamentais ou representativas de classe.

Em decorrência do trabalho anteriormente desenvolvido na ANVISA, a SOBED por intermédio da sua comissão específica, participa ativamente do grupo de estudos formado também por representantes das demais especialidades que atuam em atos médicos endoscópicos por vias exclusivamente naturais, na confecção de proposta de Resolução para estes serviços. Trabalho quase que totalmente concluído e prestes a entrar em consulta pública, que embora não crie novas regras, sintetiza as normas existentes e dá as diretrizes fundamentais para serviços de qualidade.

Também fomos ao Conselho Federal de Medicina (CFM) para participar da atualização do manual de fiscalização dos serviços médicos. Nesta reunião foram colocadas as metas daquela Comissão do Conselho, entre as quais, a firme intenção de atuação na melhora das condições de trabalho do médico tanto na rede pública como privada. Por outro lado, tivemos oportunidade de colocar as dificuldades da especialidade abordando temas relevantes como relações com a Medicina Suplementar, vigilâncias sanitárias, outros conselhos profissionais, auditores, serviços de má qualidade, dentre outros. O material solicitado pelo CFM foi entregue antes do prazo estipulado, onde reforçamos pontos importantes para o exercício da especialidade e temos que aguardar pelos resultados.

Os próximos passos, além de outras metas que estabelecemos para a atual gestão, incluem a Agência Nacional de Saúde ANS, que desde sua criação até hoje, tem sistematicamente negligenciado a relação de equilíbrio financeiro entre prestadores e tomadores de serviços, condenando os serviços e médicos sem poder econômico, a arcarem com os custos cada vez mais elevados da assistência à saúde. Muitos dos descumprimentos das normas reguladoras têm neste desequilíbrio sua origem, com alguns resultados dramáticos.

Temos um longo caminho pela frente, pois perdemos muito ao longo dos anos e recuperar parte do que ficou no passado, por toda a classe médica, necessitará de um esforço imenso, que não pode ser interrompido, de todas as instituições médicas e principalmente dos profissionais médicos. As vitórias são conseguidas a duras penas com uma lentidão inacreditável, mas cruzar os braços e esperar que outros façam nosso trabalho não é solução aceitável.

Carlos Alberto CAPPELLANES*

Cappelanes CA. Trajectory and disadvantage of an speciality medical society. Arq Gastroenterol. 2010;47(3):217-8.

HEADINGS - Societies, medical. Endoscopy, digestive system. Endoscopes, gastrointestinal. Equipment contamination. Disinfection.

\section{REFERÊNCIA}

1. Barbosa JM, Souza ACS, Tipple AFV, Pimenta FC, Leão LSNO, Silva SRMC Endoscope reprocessing using glutaraldehyde in endoscopy services of Goiania, Brazil. Arq Gastroenterol. 2010;47(3):219-24.

* Presidente da SOBED, Gestão 2008-2010 